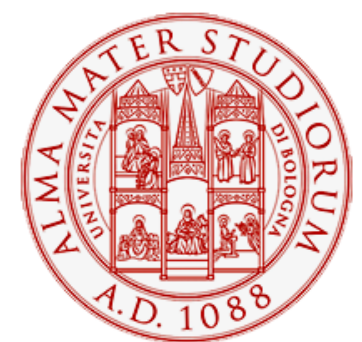

Alma Mater Studiorum - Università di Bologna DEPARTMENT OF ECONOMICS

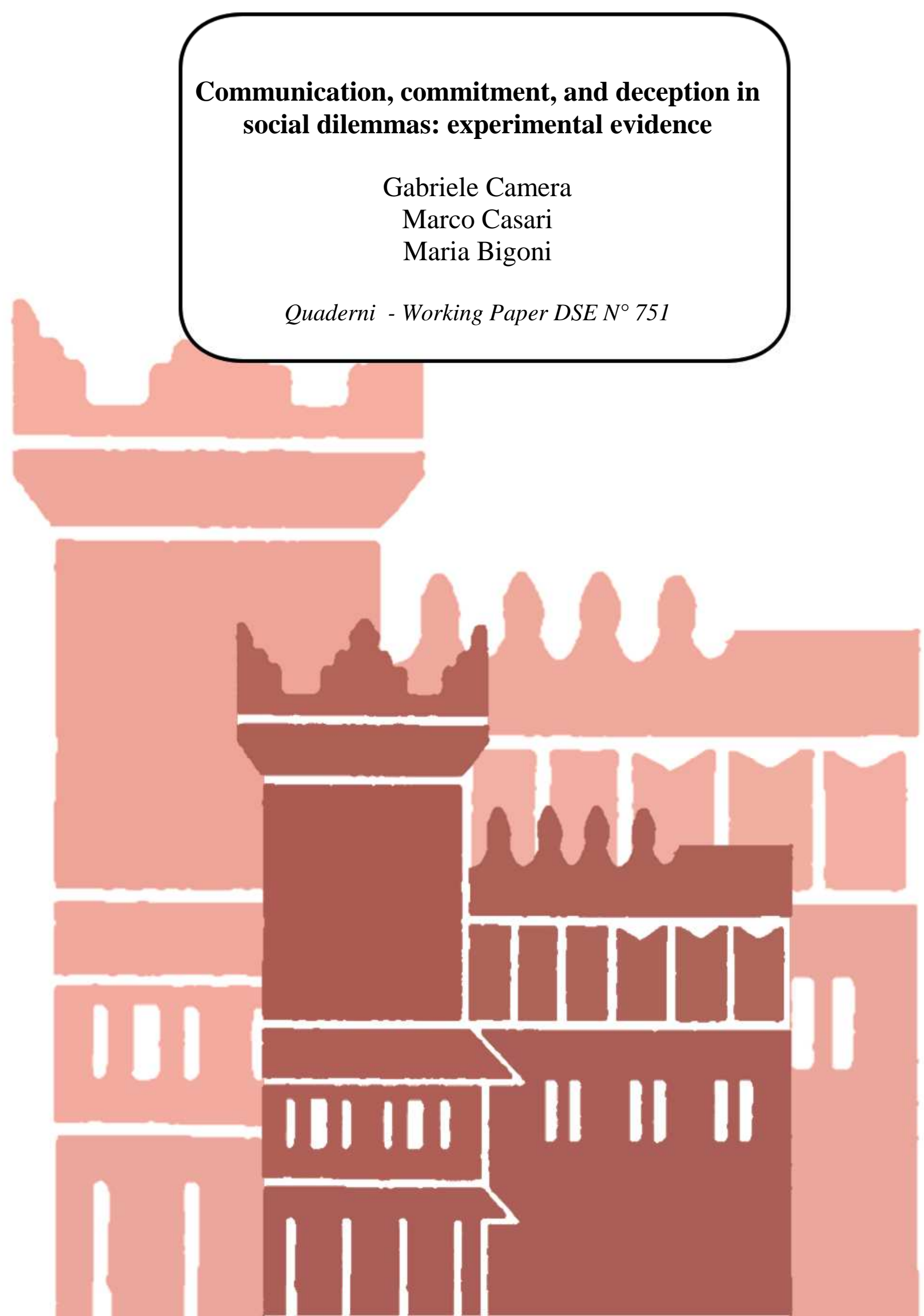




\title{
Communication, commitment, and deception in social dilemmas: experimental evidence
}

\author{
Gabriele Camera, Marco Casari, and Maria Bigoni*
}

13 May 2011

\begin{abstract}
Social norms of cooperation are studied under several forms of communication. In an experiment, strangers could make public statements before playing a prisoner's dilemma. The interaction was repeated indefinitely, which generated multiple equilibria. Communication could be used as a tool to either signal intentions to coordinate on Pareto-superior outcomes, to deceive others, or to credibly commit to actions. Some forms of communication did not promote the incidence of efficient Nash play, and sometimes reduced it. Surprisingly, cooperation suffered when subjects could publicly commit to actions.
\end{abstract}

Keywords: coordination, cheap-talk, deception, indefinitely repeated game, social norms

JEL codes: C90, C70, D80

\section{Introduction}

Communication has a positive connotation in economics. Behavioral economists have shown that non-binding pre-play communication can be a powerful tool to coordinate actions and to promote welfare in social dilemmas (Ostrom, Walker, and Gardner, 1992). This study is an experiment on if and how communication can promote the emergence of social norms of cooperation when subjects do not know the reputation of others. It examines the use of several communication technologies as a tool to either signal intentions to coordinate on Pareto-superior outcomes, to deceive others, or to build trust by credibly committing to actions.

\footnotetext{
* Camera: Purdue University; Casari: University of Bologna, Piazza Scaravilli 2, 40126 Bologna, Italy, Phone: +39-051-209-8662, Fax: +39-051-209-8493, marco.casari@unibo.it; Bigoni: University of Bologna, Piazza Scaravilli 2, 40126 Bologna, Italy, Phone: +39-051-2098135, Fax: +39-051-0544522, maria.bigoni@unibo.it. We thank Matthias Sutter and seminar participants at ESA Tucson 2010 and University of Innsbruck for useful comments. Financial support for the experiments was provided by Purdue's CIBER. This draft was completed while G. Camera was visiting the University of Siena as a Fulbright scholar.
} 
There exists an experimental literature that has explored the role of cheap-talk as a tool to signal intentions. The focus has been largely on two distinct issues: how communication can help to solve coordination problems (e.g., Cooper, et al. 1992 or, more recently, Blume and Ortmann, 2007), and how it can behaviorally discourage opportunism to improve outcomes in social dilemmas (e.g., Ostrom, 2000 or, more recently, Strassmair and Sutter, 2009). The present study makes several contributions. First, it analyzes communication when subjects' interaction was indefinitely repeated. The stage game was a prisoner's dilemma. Its repetition induced multiple equilibria ranging from full defection to the efficient outcome (folk theorem). This raises the issue of coordination along with the issue of opportunism. These issues present formidable obstacles to efficiency, from an empirical standpoint (Camera and Casari, 2009, Duffy and Ochs, 2009). Second, the design adopted makes it transparent that communication can be used in two opposing ways: as a coordination device, for those who are motivated by long-run efficiency, and as a tool for deception, for those who are tempted by short-run gains. Other types of experiments are less appropriate to study deception. For example, in coordination games there is no incentive to misrepresent intentions, even when there is conflict of interest (e.g., battle of the sexes). Moreover, cooperative messages should not be credible in finitely repeated social dilemmas because, among self-interested agents, only defection is consistent with equilibrium. In contrast, in our design, though subjects are constantly tempted by defection, cooperation is also part of equilibrium.

This study reports that some forms of structured communication had a negative impact on cooperation, even if the efficient outcome was an equilibrium. This result is novel and can be ascribed to the conflicting short and long-run incentives confronting the subjects.

A second contribution of the present study is the analysis of how communication through public statements impacts on social norms. In the experiment, an economy comprised a stable population of four subjects who interacted in pairs with changing opponents. A subject 
initially shared a message with everyone else in the economy, observed everyone's messages, and then randomly met an opponent. Before playing the prisoners' dilemma, subjects could observe past cooperation rates in the economy but not individual histories. In our setup communication could be especially valuable in implementing a social norm leading to the efficient outcome because building a reputation is impossible. This design resembles the interaction that takes place in societies where due to a variety of reasons people may not know each other and may not trust each other. In the field, transactions with these features are becoming more ubiquitous and designing decision mechanisms that can govern them is increasingly important (Baumann, 2000).

The experiment included treatments to investigate the impact of a variety of communication formats on the outcomes achieved, including free-form and structured communication. We report that structured communication did not help cooperation, relative to a no-communication setting. A possible reason for this effect is deception, i.e., the opportunity for subjects to misrepresent their intentions. ${ }^{1}$ Our design makes it easy to detect and quantify deception in communication because subjects could make a neutral public statement instead of an explicit statement of cooperation or defection, thus deception was always intentional.

To investigate whether deception undermines the usefulness of communication, we included a treatment where messages could form binding public promises of future play. By introducing the possibility of auditing, the design made voluntary commitment feasible, so that a message basically amounted to a credible pledge. The surprising result is that cooperation decreased compared to no-communication.

\footnotetext{
${ }^{1}$ Aumann (1990) and Farrell and Rabin (1996) suggest credibility of messages is key to effective communication.
} 
A main lesson is that structured communication does allow players to convey information about intended play, but it is also prone to a deceptive use, which destroys trust in the cooperative efforts of others. Another lesson from the experiment is that subjects did recognize and actively sought to solve the problem of deception through auditing. Yet, this did not raise the effectiveness of communication in sustaining social norms of cooperation. A third lesson is that public statements regarding intended play were not always effective in promoting cooperation even when full cooperation was an equilibrium. Why was structured communication ineffective? In the experiment cooperative messages were mostly perceived as a truthful signal of the senders' cooperative intentions. In addition, subjects cooperated more when they saw more cooperative messages. The drawback is that this also increased the temptation to behave opportunistically: hence, some subjects exploited communication by disguising themselves as cooperators and then defected. The resulting coexistence of truthful and deceptive uses of communication diluted the effectiveness of making public statements of cooperation as a way to coordinate on efficient Nash play.

The paper proceeds as follows: Section 2 discusses related works; Section 3 presents the experimental design and offers theoretical considerations; results are reported in Section 4; and Section 5 concludes.

\section{Literature Review}

In this section we review some recent experiments about communication that involve either coordination games or social dilemmas. ${ }^{2}$ Blume and Ortmann (2007) study finitely repeated coordination games, where a fixed group of nine subjects play a median effort game or a minimum effort game. Structured pre-play communication helps in achieving and

\footnotetext{
${ }^{2}$ For a more general overview of the effects of communication in experiments we refer the reader to Sally (1995), Crawford (1998) and Ostrom (2010).
} 
sustaining the efficient equilibrium. Their result suggests that repeated communication opportunities allow subjects to more easily coordinate on Pareto-superior outcomes, as if repetitions help subjects negotiate good outcomes.

Cason and Mui (2010) study a collective resistance game among three players, with finite and indefinite repetition. First a leader may "transgress" against one or both of two responders, who then may coordinate their individual responses through structured communication. They consider both three-subject economies, as well as nine-subject economies with random matching. Adding communication facilitates coordination and always increases the chance of achieving the efficient outcome. ${ }^{3}$

Wilson and Sell (1997) study a finitely repeated voluntary contribution mechanism in fixed groups of six participants. They study the impact that two types of information - cheap talk and observation of past actions-have on cooperation. Cheap-talk is not effective in enhancing cooperation and the authors suggest that future experiments study institutional mechanisms that bind subjects to carry the promises made via pre-play communication.

Duffy and Feltovich (2006) study cooperation in three classes of finitely repeated games: prisoner's dilemma, stag-hunt and chicken. Each economy lasts ten periods and includes twenty participants who play against changing opponents. They compare the impact of cheap talk and of observation of past actions. There are negative returns in terms of social welfare from adding one information technology, if another one is already present. In other words, the two information technologies are not complementary in their experiments.

Cooper and Kuhn (2010) study collusion in two-periods Bertrand duopoly games, with structured or free-form messages. In the first period the two subjects can send structured messages to each other before playing a social dilemma. In the second period, they play a

\footnotetext{
${ }^{3}$ There are other interesting recent studies on communication, such as Bochet et al. (2006), which studies different forms of communication in a public good game, and Bigoni, et al. (2009), which studies communication with indefinitely repeated interactions.
} 
coordination game. This second period is interpreted as the reduced-form of a continuation game with an infinite horizon. Structured communication does not raise cooperation but freeform communication does. They put forward three reasons for this effect of free-form communication: subjects (i) formulate explicit threats to punish cheating, (ii) exchange promises to cooperate, and (iii) invoke the mutual benefit of cooperation. Additionally, Cooper and Kuhn (2010) study the impact of renegotiation, by comparing economies with communication in both periods as opposed only to the first. Theory suggests that the possibility to renegotiate lowers the initial incentives to coordinate on cooperation - or collude (Abreu et al., 1993, Van Damme, 1989). Contrary to this prediction, cooperation is higher when communication occurs in both periods. ${ }^{4}$

Our paper differs from the above because it studies an indefinitely repeated prisoners' dilemma in economies of four subjects who have repeated opportunities to communicate, and have also incentives to send deceptive messages. Unlike the indefinitely repeated game in Cason and Mui (2010), where only a subset of players can exchange messages, our communication game is symmetric. Unlike the finitely repeated games in Wilson and Sell (1997) and in Duffy and Feltovich (2006), the efficient outcome is a theoretical equilibrium in our experimental economies. In Cooper and Kuhn (2010), the reduced-form adopted implies subjects act as if they are committing to strategies in the continuation game. Instead, our design explicitly encompasses indefinite duration; this allows subjects to choose from a much wider set of strategies and retains the fundamental coordination difficulties that characterize the continuation game in indefinitely repeated social dilemmas. In addition,

\footnotetext{
${ }^{4}$ In this sense, our study also contributes to a literature on collusion and renegotiation in industrial organization, as cooperation in our setup can be seen as a form of collusion. Renegotiation in our paper takes place in a stationary environment, because it always involves the same type of game, which is not a pure coordination game. We do not find evidence for a negative impact of renegotiation. Andresson and Wengstrom (2010) also investigate the effects of renegotiation and report that, in a two-stage game, pre-play communication only has a significant impact on subjects' cooperation when no renegotiation is possible, which is consistent with some of our results.
} 
subjects cannot send a private message to their opponent before play but can only send a public message of proposed play to the entire economy. After observing all messages in the economy subjects randomly meet their opponent to play the prisoner's dilemma.

Differences with previous experimental studies about repeated social dilemmas also emerges with respect to the use of deception.

There are additional elements of the design, which differentiate our study from previous papers on the subject. First, the Pareto efficient outcome in our study is an equilibrium but players may use communication deceptively because their interests are not perfectly aligned. This contrasts with deception in finitely repeated social dilemmas, where the unique equilibrium is defection. Second, our design incorporates a structured communication protocol that includes both a common language suggestive of actions (explicit messages), as well as language that is not suggestive of actions (neutral messages). This helps in detecting and in quantifying a deceptive use of communication. Third, our design introduces a mechanism to study whether the ability to make binding promises enhances the effectiveness of communication in achieving superior outcomes.

\section{Experimental Design and Theoretical Considerations}

There are five treatments that differ in the availability and characteristics of the communication means available. The treatments are No-communication, Messages, Multiple Messages, Pledge, and Chat (Table 2). Stage game, continuation probability, and matching protocols were identical across treatments. In particular, the efficient outcome is a sequential equilibrium in all treatments. We first present the No-communication treatment. The other treatments, which will be later described, include an additional communication stage. 
The stage game is a standard prisoner's dilemma with payoffs determined according to Table 1. In the instructions and in the experiment we adopted the neutral labels $Y$ for cooperate and $Z$ for defect.

\begin{tabular}{ccc}
\hline Player 1, & $Y$ (cooperate) & $Z$ (defect) \\
Player 2 & & \\
\hline$Y$ (cooperate) & 25,25 & 5,30 \\
$Z$ (defect) & 30,5 & 10,10 \\
\hline
\end{tabular}

Table 1: The stage game

A supergame or cycle (as it was called in the experiment) consists of an indefinite interaction among subjects achieved by a random continuation rule in the footsteps of Roth and Murninghan (1978). A cycle that has reached period $t$ continues into period $t+1$ with probability $\delta=0.95$, so the interaction is of finite but uncertain duration. The continuation probability $\delta$ is interpreted as the discount factor of a risk-neutral subject. The expected duration of a cycle is $1 /(1-\delta)=20$ periods, and in each period the cycle is expected to go on for 19 additional periods. In the experiment at the end of each period the computer drew a random integer between 1 and 100, using a uniform distribution, and showed it to all session participants. The cycle terminated with a draw of 96 or of a higher number.

Before taking an action, subjects could observe all past actions taken in their economy, but could not see individual histories. A table on the screen listed everyone's actions in random order, period by period. Subjects could identify neither their current nor their past opponents. That is to say, subjects could not use strategies based on reputation. However, the parameterization selected guarantees that the efficient outcome is a sequential equilibrium in all treatments because subjects can use the threat of economy-wide defection to police deviations from cooperation. For a proof of this claim and further details we refer the reader to the analysis in the anonymous public monitoring treatment in Camera and Casari (2009). 
Each experimental session involved twenty subjects and five cycles. We built twenty-five economies in each session by creating five groups of four subjects in each of the five cycles. This protocol repeatedly exposes subjects to the same decisional situation, hence it allows for learning while keeping under control contagion effects across cycles. In every cycle each economy included only subjects who had neither been part of the same economy in previous cycles nor were part of the same economy in subsequent cycles. Subjects did not know how groups were created but were informed that no two participants ever interacted together for more than one cycle. This matching protocol across cycles is important to minimize the possibility of contagion effects. In our study each subject played five cycles so that subjects may have indirectly shared a common past opponent only after the second cycle.

For the whole duration of a cycle subjects were randomly matched in pairs in each period and interacted exclusively with the other three members of their economy. At the beginning of each period of the cycle, the economy was randomly divided into two pairs in such a way that each subject had one third probability of meeting any of the three other participants in her economy. By design, cycles for all economies terminated simultaneously.

All 180 subjects were recruited through e-mail and in-class-announcements. The sessions were run at Purdue University's VSEEL lab. No eye contact was possible among subjects. Instructions were read aloud with copies on all desks. A copy of the instructions is in the Appendix. Average earnings were $\$ 23.90$ and there were no show-up fees. A session lasted on average 88 periods for a running time of about 3 hours, including instruction reading and a quiz. Each session had 20 participants and 5 cycles.

\subsection{Treatments}

In treatments Messages, Multiple Messages, Pledge and Chat, subjects had the opportunity of sending a public message. We allowed subjects to communicate in the first period of the cycle and then also during the course of the cycle. In this manner 
communication not only can have the role of signalling intention but can also have a reassuring role (see the discussion in Crawford, 1998). Messages were simultaneously made public and in some treatments repeated rounds of communication occurred before playing the stage game (Table 2). This was done because previous results suggest that repeated rounds of communication help subjects achieve a consensus on messages (Blume and Ortmann, 2007). In all treatments, interactions and communication were anonymous. Communication was free-form in the Chat treatment; it was structured in all other treatments, as described below.

\begin{tabular}{|c|c|c|c|c|c|c|c|c|c|}
\hline & \multicolumn{2}{|c|}{$\begin{array}{c}\text { No- } \\
\text { communication }\end{array}$} & \multicolumn{2}{|c|}{ Messages } & $\begin{array}{l}M u \\
M e s\end{array}$ & $\begin{array}{l}\text { Itiple } \\
\text { ssages }\end{array}$ & \multicolumn{2}{|c|}{ Pledge } & Chat \\
\hline $\begin{array}{l}\text { Communication } \\
\text { frequency }\end{array}$ & $\mathrm{n} /$ & & Every 1 & period & & $\begin{array}{l}\text { ery } 4 \\
\text { riods }\end{array}$ & Every 4 & 4 periods & $\begin{array}{l}\text { Every } 4 \\
\text { periods }\end{array}$ \\
\hline Message space & $\mathrm{n} /$ & & $\begin{array}{r}\text { "Y', “'Z, } \\
\text { sur }\end{array}$ & e" or "not & $\begin{array}{c}4 \text { itera } \\
\text { "Y", } \\
\text { "not }\end{array}$ & $\begin{array}{l}\text { ations of } \\
\text { "'Z," or } \\
\text { t sure" }\end{array}$ & $\begin{array}{l}\text { "Y', ' } \\
\text { "not }\end{array}$ & $\begin{array}{l}\text { "Z" or } \\
\text { sure" }\end{array}$ & $\begin{array}{l}\text { Free- } \\
\text { form text }\end{array}$ \\
\hline Auditing & $\mathrm{n} /$ & & $\mathrm{n} /$ & & $\mathrm{n} /$ & $/ \mathrm{a}$ & $\begin{array}{r}\text { Pay } 1 \mathrm{p} \\
\text { dedu } \\
\text { points } \\
\text { anyone } \\
\text { choi } \\
\text { sugge } \\
\text { dif }\end{array}$ & $\begin{array}{l}\text { point to } \\
\text { dct } 10 \\
\text { s from } \\
\text { e whose } \\
\text { ice \& } \\
\text { estion } \\
\text { ffer }\end{array}$ & $\mathrm{n} / \mathrm{a}$ \\
\hline Session dates & 27.4 .05 & 1.9 .05 & 15.2.07 & 28.4.10 & 9.2 .07 & 3.4 .10 & 5.4 .07 & 11.4 .07 & 23.2 .07 \\
\hline No. of periods & 129 & 125 & 109 & 42 & 35 & 39 & 75 & 79 & 159 \\
\hline
\end{tabular}

Table 2: Treatments and Sessions

Notes to Table 2: The sessions run on 27.4.05 and 1.9.05 are also analyzed in Camera and Casari (2009)

Messages treatment. In every period there was a pre-play communication stage, called the "suggestions stage" in the instructions. Each subject had the opportunity to suggest a play ("Y," "Z," or "not sure") for everyone in the economy for the current period, by making a message public, at no cost. A message included three parts: a suggestion ("Y," "Z," or "not 
sure") for the subject herself, for her anonymous match, and for everyone else. ${ }^{5}$ Subjects were informed that the suggestion stage gave them the opportunity to suggest choice $\mathrm{Y}$ or $\mathrm{Z}$ for themselves, for their match, and for everyone else in their economy. If subjects wanted to avoid sending a specific suggestion Y or Z, then they could leave all options to "not sure," which was the default message. Because the mapping between a " $Y$ " or " $Z$ " message and the corresponding actions is clear, we refer to those as explicit messages. Instead, we refer to "Not sure" as a neutral message, to which different subjects could attach a different meaning. When choosing what action to take in the prisoner's dilemma game, subjects could see on their screen everyone's messages. In keeping with the strict anonymous protocol of the experiment, the sender of the message was not identifiable.

Multiple Messages treatment. Subjects entered the pre-play communication stage at the beginning of period one, and then every four periods. To help subjects achieve a consensus on the messages and to facilitate coordination on play, in the communication stage each subject had repeated opportunities to make a message public, at no cost. The structure of the message was as in the Messages treatment, although the communication stage comprised four separate steps. In expectation subjects had the same number of opportunities for communication as in the Messages treatment, although with a different timing. In step one, each subject sent the three-part message described in the Messages treatment ("Y," "Z," or "not sure"). In step two, first subjects saw on their screen all messages sent in step one by everyone in the economy, and then had the opportunity to revise their step-one message. Steps three and four followed the same procedure. That is to say, subjects had three separate opportunities to revise their message after seeing the messages of others. After their third and last revision, subjects could see on their screen all messages by everyone in the economy,

\footnotetext{
${ }^{5}$ We will refer to the first part of the message (message sent "for oneself") as a message signaling intentions of play of the sender; we will refer to the other parts of the message as a message sent to suggest play to others. The analysis focuses on the first part of the message, i.e., messages sent "for oneself."
} 
before choosing their action in the Prisoner's dilemma. Once again, the sender of the message was never identifiable during this communication process.

Pledge treatment. Subjects entered the pre-play communication stage at the beginning of period one, and then every four periods. In the communication stage, each subject had one opportunity to make a message public, at no cost. The structure of the message and of the communication stage was identical to that in the Messages treatment. However, this treatment introduced a mechanism that made it possible for messages to be interpreted as binding suggestions for future play. This was done as follows. In every period of the cycle, when subjects were called to chose between action $Y$ and $Z$ in the Prisoner's dilemma, subjects were also simultaneously asked to decide whether or not to audit, i.e., to verify the concordance between messages sent in the last communication stage and the actions chosen in the period. If a subject chose to audit, then she paid 1 point in order to activate the auditing mechanism for that period. The mechanism would then compare actions and suggestions in the entire economy. Through this auditing mechanism, all subjects in the economy (including the one who audited) suffered a ten-point loss if in the last communication stage (i) they either suggested $Y$ for themselves and chose $Z$ currently, or (ii) they suggested $Z$ for themselves and then chose $Y$. No losses were incurred by subjects who selected the neutral message "not sure" for themselves, and by subjects whose choices and suggestions (for themselves) were concordant. If at least one person in the economy chose to audit, then at the end of the period everyone in the economy could see how many subjects incurred a loss.

Chat treatment. Subjects entered the pre-play communication stage at the beginning of period one, and then every four periods. Communication was free-form and took place through a chat box that remained open for two minutes. ${ }^{6}$ In sending messages, subjects were instructed to be civil to one another, not to use profanities, and not to identify themselves in

\footnotetext{
${ }^{6}$ We thank John Kagel for having kindly provided the chat program.
} 
any manner. Each sender of the chat message was identified by a number which changed every period, to avoid direct identification of subjects during the communication stage. ${ }^{7}$

\subsection{Theoretical considerations}

Our design admits multiple equilibria, ranging from full defection to the efficient outcome. This follows from the Folk Theorem-type results obtained in the matching games studied in Kandori (1992) and Ellison (1994). Given that there is public monitoring of actions in the economy, the efficient outcome can be sustained as a sequential equilibrium for all discount factors greater than 0.25. For risk-neutral agents, the discount factor in the experiment corresponds to the continuation probability, i.e., 0.95 . The proof is built around the conjecture that everyone employs a social norm of cooperation based on the following trigger strategy: subjects start period one cooperating and keep cooperating as long they do not observe defections. If a defection is observed in the economy, then subjects defect forever. See the analysis of anonymous public monitoring in Camera and Casari (2009).

Several remarks are in order. First, the introduction of structured communication in the Messages, Multiple Messages and Pledge treatments, and of free-form communication in the Chat treatment does not remove the multiplicity of equilibria that exists in the indefinitely repeated game without communication. Indeed, subjects can simply choose to ignore any message received. On the one hand, due to public monitoring, the possibility to send public messages does not increase the speed with which a defection can be communicated to the rest of the economy. On the other hand, public messages can facilitate a reversion to cooperation if defections have occurred.

Second, in contrast to Chat, structured communication imposes important constraints: it does not allow conveying individual histories, strategies, approval or disapproval. In

\footnotetext{
${ }^{7}$ The instructions for the chat treatment warned subjects not to identify themselves. Despite this requisite, subject could in principle identify themselves indirectly (e.g., by using specific language).
} 
particular, with structured communication subjects cannot convey explicit threats for defections, which is crucial when incentives to behave opportunistically exist. Hence, despite the fact that actions $Y$ and $Z$ are both part of a sequential equilibrium, structured messages are not necessarily credible (see the discussion in Farrell and Rabin, 1996). To fix ideas, a subject who is following an "always defect" strategy may send a message $Y$ simply to induce her opponent to cooperate. That is to say, structured messages are not necessarily self-signaling and self-committing and can be outright deceptive. Hence, to quantify the incidence of deception through structured communication, our design includes the possibility to send messages with a common meaning (an explicit message, reflecting an action label) as well as a message without a common meaning (the neutral message "not sure").

Third, in the Pledge treatment deception could be eliminated entirely through auditing. Subjects had the option to activate an institution ensuring messages are self-committing. If someone audited, then the sender of a $Y$ or $Z$ message had a sufficient incentive to behave accordingly, because auditing imposed significant losses on those subjects found to have behaved inconsistently. Sending a message of cooperation and then defecting gave a subject at most 30 points (if the opponent cooperated) minus 10 points of sanction. The active use of auditing cannot sustain the efficient outcome because auditing is costly. In addition, in equilibrium there is no reason to use auditing as a precautionary measure because it involves a personal cost and generates no additional benefits.

While in theory the Pledge treatment should not reduce the use of deceptive messages, in the experiment we expect a positive impact of this institution on cooperation, in light of previous experimental results on costly personal punishment.

\section{Results}

We report six main results. 
Result 1: Structured communication did not significantly raise cooperation relative to Nocommunication. In contrast, free-form communication supports almost full cooperation.

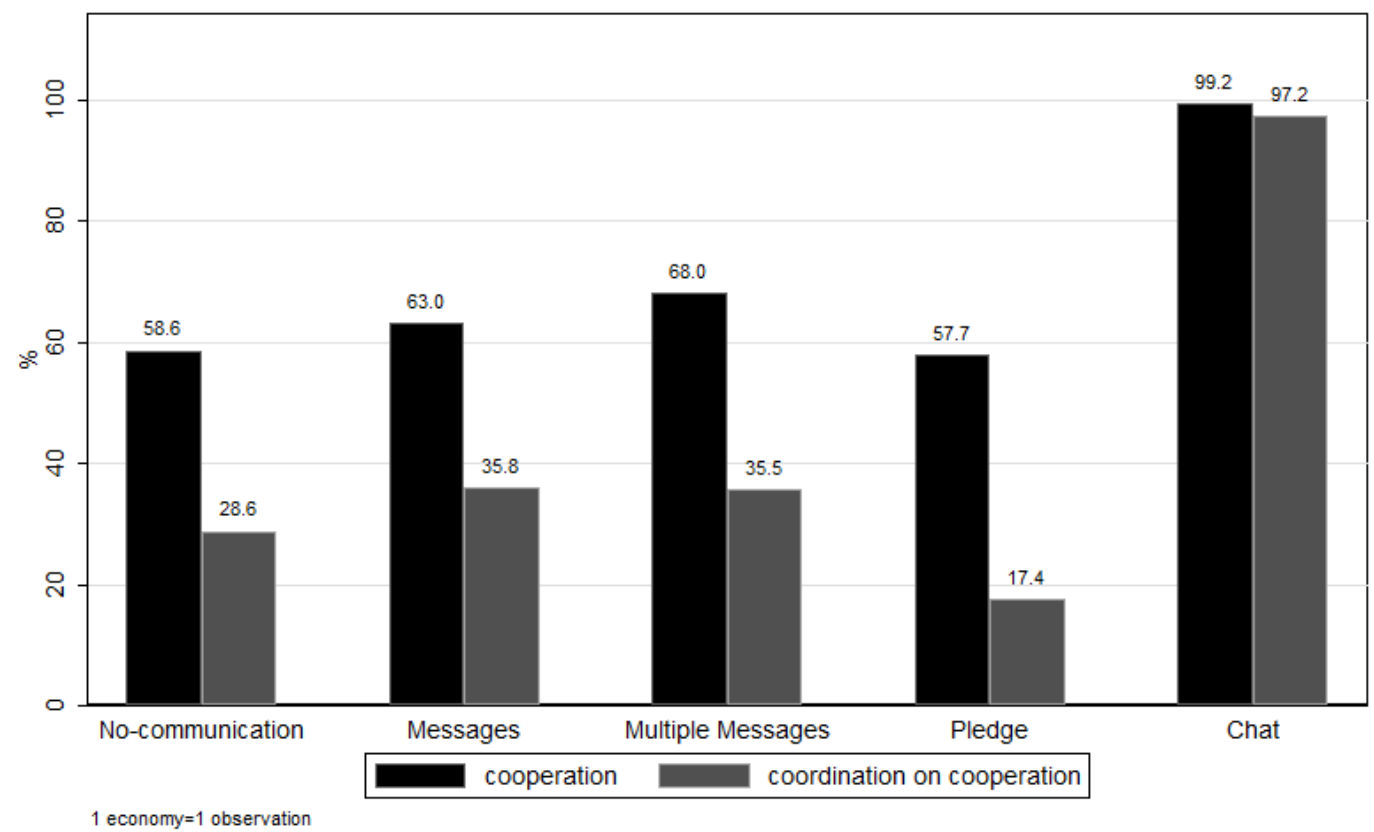

Figure 1: Cooperation rates by treatment

Notes to Figure 1: The mean cooperation rate is the fraction of cooperative actions. There is coordination on cooperation in a period, when everyone in the economy cooperated.

Figure 1 and Tables 3-4 provide support for Result 1 in reference to average cooperation and average coordination on cooperation. The level of cooperation in an economy is the fraction of $\mathrm{Y}$ actions in that economy. Instead, the level of coordination on cooperation in an economy is the fraction of periods in which all subjects in that economy cooperated (Table $3) .{ }^{8}$ When comparing average cooperation rates in all periods, the No-communication

\footnotetext{
${ }^{8}$ The mean cooperation rate for economy $k=1, . ., n$ is measured by coding a cooperative action as 1 , and a defection as 0 . Define the action $a_{i t}{ }^{k} \in\{0,1\}$ of subject $i=1, . .4$ in period $t=1, . ., T^{k}$ of the economy $k$; average cooperation in economy $k$ is $c_{k}=\frac{1}{4 \mathrm{~T}^{k}} \sum \sum a_{i t}^{k}$ between zero and one, and across economies is $c=\frac{1}{n} \sum_{k=1}^{n} c_{k}$.
} Thus, although economies have different length $T^{k}$, they are given equal weight in our measure $\mathrm{c}$ of average 
treatment is not significantly lower than the Messages, Multiple Messages, and Pledge treatments. A Kruskal-Wallis test does not reject the null hypothesis that observations from the four treatments are drawn from the same population ( $p$-value $>0.1, n=200$ ). This result is confirmed by pairwise comparisons with the No Communication treatment (Mann-Whitney tests, $\mathrm{n} 1=\mathrm{n} 2=50, \mathrm{p}$-value $>0.10) .{ }^{9}$ By contrast, the Chat treatment exhibits average cooperation rates that are more than 30 percentage points above all other treatments, and this difference is significant (Kruskal-Wallis test on the five treatments, $n=225$, $p$-value $<0.01$; pairwise Mann-Whitney, $\mathrm{n} 1=25, \mathrm{n} 2=50$, $\mathrm{p}$-value $<0.01){ }^{10}$

Similarly, we fail to find evidence that structured communication significantly increases the level of coordination on cooperation with respect to the No Communication treatment (Kruskal-Wallis test on four treatments, $n=200$, p-value $>0.1$; Mann-Whitney pairwise tests, $\mathrm{n} 1=\mathrm{n} 2=50, \mathrm{p}$-value $>0.10$ ). Furthermore, in the case of the Pledge treatment, coordination on cooperation is significantly lower than in any other treatment (Mann-Whitney pairwise tests, $\mathrm{n} 1=\mathrm{n} 2=50, \mathrm{p}$-value $<0.10)$.

\begin{tabular}{lccc}
\hline Treatment & $\begin{array}{c}\text { Coordination Coordination } \\
\text { on defection on cooperation }\end{array}$ & \\
\hline No-communication & 0.117 & 0.286 & 0.597 \\
Structured communication & 0.109 & 0.296 & 0.595 \\
\hline
\end{tabular}

Table 3: Coordination in an economy

cooperation. Similarly, in economy $k$ the coordination on cooperation rate is $c c_{k}=\frac{1}{T^{k}} \sum_{t=1}^{T^{k}} \prod_{i=1}^{4} a_{i t}^{k}$, and the average across economies is $c c=\frac{1}{n} \sum_{k=1}^{n} c c_{k}$.

${ }^{9}$ Unless otherwise stated, in the Result section the unit of observation is an economy in a cycle. The results of the statistical tests in the paper rely on the assumption that all observations are independent. All tests are twosided.

${ }^{10}$ An independent coder analyzed the chat messages to assess whether subjects in the chat treatment communicated contingent strategies. We report that in every economy subjects discussed a plan of action directed toward achieving cooperation. However, only in $40 \%$ of the economies subjects discussed a possible punishment strategy to be implemented in the event of a deviation from the plan of action. This suggests that communicating contingent strategies is not essential to achieve $100 \%$ cooperation. 
Notes to Table 3: There is coordination in an economy when all four subjects select the same action in the period. The difference among the rates of coordination on defection is not significant ( $p$-value: 0.1046, $n 1=50$, $n 2=150)$.

More evidence along these lines comes from measuring cooperation through a probit regression (Table 4). Regressions in Table 4 include random effects at the subject level and cluster at the session level in order to take into account the interactions of choices across individual subjects and groups. Table 4 also fails to find evidence that structured communication increases cooperation relative to No-communication.

\begin{tabular}{|c|c|c|c|c|c|c|}
\hline \multirow{2}{*}{$\begin{array}{l}\text { Dependent variable: } \\
1=\text { Cooperation } \\
0=\text { Defection }\end{array}$} & \multicolumn{2}{|c|}{$\begin{array}{l}\text { All treatments, } \\
\text { All periods }\end{array}$} & \multicolumn{2}{|c|}{$\begin{array}{l}\text { All treatments except } \\
\text { Chat, Periods } 1 \text { only }\end{array}$} & \multicolumn{2}{|c|}{$\begin{array}{c}\text { All treatments except } \\
\text { Chat, } \\
\text { All periods }\end{array}$} \\
\hline & (1a) & $\begin{array}{c}\text { (1b) } \\
\text { marginal } \\
\text { effects }\end{array}$ & (2a) & $\begin{array}{c}(2 b) \\
\text { marginal } \\
\text { effects }\end{array}$ & (3a) & $\begin{array}{c}(3 \mathrm{~b}) \\
\text { marginal } \\
\text { effects }\end{array}$ \\
\hline \multicolumn{7}{|l|}{ Treatment dummies } \\
\hline Messages & $\begin{array}{l}-0.313 * * * \\
(0.087)\end{array}$ & -0.087 & $\begin{array}{l}0.486^{*} \\
(0.259)\end{array}$ & 0.094 & $\begin{array}{l}-0.255^{* *} \\
(0.106)\end{array}$ & -0.088 \\
\hline Multiple Messages & $\begin{array}{l}-0.079 \\
(0.127)\end{array}$ & -0.020 & $\begin{array}{l}0.621 * * * \\
(0.218)\end{array}$ & 0.112 & $\begin{array}{l}-0.060 \\
(0.337)\end{array}$ & -0.020 \\
\hline Pledge & $\begin{array}{l}-0.803 * * * \\
(0.171)\end{array}$ & -0.264 & $\begin{array}{l}-0.035 \\
(0.233)\end{array}$ & -0.009 & $\begin{array}{l}-0.301 * \\
(0.157)\end{array}$ & -0.106 \\
\hline Chat & $\begin{array}{l}2.572 * * * \\
(0.088)\end{array}$ & 0.159 & & & & \\
\hline
\end{tabular}

N. of others signaling a cooperative intention X treatment dummy

Messages

$0.280 * * * \quad 0.090$

$(0.020)$

Multiple Messages

$0.229 \quad 0.074$

(0.173)

Pledge

$0.332 * * * \quad 0.107$

(0.023)

Cycle dummies

cycle 2

$-0.020$

$-0.005$

$-0.536 * * \quad-0.167$

0.020

0.007

(0.287)

(0.234)

(0.282)

cycle 3

0.244

0.052

$-0.435 * *$

$-0.131$

0.247

0.073

(0.164)

(0.202)

(0.152)

cycle 4

0.242

0.052

$-0.130$

$-0.035$

$0.391^{* *}$

0.109

(0.207)

(0.248)

(0.199)

cycle 5

0.399

0.078

$-0.000$

$-0.000$

$0.494 *$

0.131

(0.268)

$(0.255)$

(0.285)

Duration of previous cycle

$0.011 * * \quad 0.003$

$0.010 * * * \quad 0.002$

$0.011 * * * \quad 0.003$

(0.005)

(0.003)

(0.003) 


\begin{tabular}{llll} 
Constant & $0.787^{* *}$ & $0.802 * *$ & 0.132 \\
& $(0.320)$ & $(0.324)$ & $(0.254)$ \\
\hline Log-likelihood & -6377.13 & -362.12 & -6185.21 \\
Observations & 15840 & 800 & 12660 \\
\hline
\end{tabular}

\section{Table 4: Treatment and communication effects}

Notes to Table 4: Probit regression. The regression includes dummies for periods 2,3,4,5, 6-10, 11-20, 21-30 and above 30, which are not reported in the table. The regression was run with GLLAMM in Stata v.10. Standard errors in parentheses, * significant at 10\%; ** significant at 5\%; *** significant at 1\%

Table 4, column 1 reports the results from a probit regression that explains the individual choice to cooperate (1) or not (0) using treatment dummies and other regressors that control for fixed effects (cycles, periods within the cycle, duration of the previous cycle). The availability of structured communication is associated with a decrease in the cooperation rate for the representative subject, which is significant at one percent level in the Pledge and Messages treatments and not significant in the Multiple Messages treatment. ${ }^{11}$

The novel aspect of Result 1 is that communication is sometimes detrimental to cooperation even when cooperation is part of a Nash equilibrium. Theory suggests that, at worst, cheap talk communication may be ineffective where messages may not be credible (Aumann, 1990). In line with theory, previous empirical evidence on structured communication documented that, in coordination games, it generally promotes coordination on the Pareto-efficient outcome, especially if the game is repeated (Blume and Ortmann, 2007). In our experiment repeated communication opportunities did not promote efficient Nash play, and sometimes worse outcomes were reached than with no communication. Similar findings for structured communication are reported in finitely repeated social dilemma experiments where, however, cooperation is not part of a Nash equilibrium (Wilson and Sell, 1997, Duffy and Feltovich, 2006).

\footnotetext{
${ }^{11}$ The difference in cooperation rates between No-communication and Messages is significant according to the probit regression in Table 4 (col.1) but not according to the above non-parametric test. While in the regression one observation is a single choice by a subject in a period, in the test it is the average choice in an economy. As a consequence, the regression gives more weights to longer cycles.
} 
Result 2: The possibility of renegotiation did not significantly reduce initial cooperation.

Periodic opportunities to communicate offer the possibility to re-coordinate on cooperation after a failed attempt ("renegotiate"). This would not be the case if communication could take place only once at the beginning of the cycle. The possibility of renegotiation weakens the credibility of punishment threats for deviation from a cooperative strategy. Hence, theory predicts lower initial cooperation rates in treatments with communication than without (e.g., VanDamme, 1989, Abreu, Pierce, and Stacchetti, 1993).

Cooperation in period 1 was $70.5 \%$ in No-communication, $78.0 \%$ in Messages, $76.5 \%$ in Multiple Messages, $65.0 \%$ in Pledge, $100.0 \%$ in Chat. A Kruskal-Wallis test rejects the hypothesis that observations from the first four treatments are drawn from the same distribution ( $n=200, p$-value: 0.06 ). Initial cooperation rates in Pledge are significantly lower than in Messages and Multiple-messages (Mann-Whitney tests, $\mathrm{n} 1=\mathrm{n} 2=50, \mathrm{p}$-values: 0.016 and 0.04 , respectively).

Table 4, column 2 provides further supports for Result 2. Results from a probit regression explaining the individual choices in period 1 always highlight no significant decrease in initial cooperation, and a significant increase in some treatments. This does not support the conjecture that the possibility to renegotiate lowers initial cooperation rates. Result 2 answers a methodological question raised in Cooper and Kuhn (2010) about the possibility of studying collusion in finitely repeated games to draw inference on infinitely repeated games. We report that some of their main results on the effects of communication still hold in an indefinitely repeated setting. In particular, we confirm that the possibility of renegotiation is not detrimental to cooperation, as opposed to a no-communication setting. 
Result 3: Structured messages signaled intentions: subjects tended to act in accordance with their own messages. Moreover, subjects' choices were affected by others' messages.

Table 5 and Figure 2 provide support for Result 3. Subjects seized on communication opportunities when available, by widely sending public messages that explicitly stated their intended play (i.e., a message $\mathrm{Y}$ or $\mathrm{Z}$, for structured communication). In particular, with structured communication, subjects rarely made public statements of defection.

The opportunity to send an explicit public message is used between $36.6 \%$ and $88.0 \%$ of instances, depending on the treatment, as seen in Figure 2, which illustrates the fraction of 'not sure' messages. Messages of defection in the structured communication treatments amount to less than $5.1 \%$ of the instances in which communication could take place (154/3020 for Messages, 20/440 for Multiple Messages and 41/860 for Pledge, Table 5).

In all treatments, there is coherence at the individual level between the statements made public and choices subsequently taken. Recall that there is no direct cost from choosing an action different from the message sent. Only in the Pledge treatment the chance of being audited introduces such a cost as an endogenous possibility.

In the Messages treatment, while a subject who publicly signaled her intention to cooperate (message "Y") did cooperate in $64.1 \%$ of periods immediately following communication, a subject who signaled defection (message " $Z$ ") cooperated only in $7.1 \%$ of cases (Table 5). In the Multiple Messages and Pledge treatments there is an even stronger coherence between messages sent and subsequent choices. As a consequence, subjects could rely on public statements made by others about their intended play to forecast behavior in the economy. Our data show that actions are a function of the type of messages seen.

Table 5 shows that a subject cooperated more frequently the greater was the number of cooperative messages observed. For example, in the Messages treatment, a subject who sent a neutral message ("not sure") cooperated in $62.0 \%$ of cases when everyone else sent a 
cooperation message and $40.1 \%$ in all other instances. Subjects that made public a neutral statement cooperated less than the economy average. We will say that a message is informative if it is positively or negatively correlated with a specific action.

\begin{tabular}{|c|c|c|c|}
\hline \multirow{2}{*}{$\begin{array}{l}\text { Subject's message about } \\
\text { her intended play }\end{array}$} & \multirow{2}{*}{$\begin{array}{l}\text { Cooperation } \\
\text { frequency }\end{array}$} & \multicolumn{2}{|c|}{$\begin{array}{c}\text { Cooperation frequency conditional on the } \\
\text { messages sent by others }\end{array}$} \\
\hline & & $\begin{array}{l}\text { zero, one, or two } \\
\text { Y messages }\end{array}$ & $\begin{array}{c}\text { Three } \\
\text { Y messages }\end{array}$ \\
\hline \multicolumn{4}{|l|}{ Messages } \\
\hline Not sure & 0.449 & $0.401(800)$ & $0.620(221)$ \\
\hline Y (cooperation) & 0.641 & $0.577(1273)$ & $0.783(572)$ \\
\hline $\mathrm{Z}$ (defection) & 0.071 & $0.058(120)$ & $0.118(34)$ \\
\hline Total & 0.547 & $0.484(2193)$ & $0.712(827)$ \\
\hline \multicolumn{4}{|l|}{ Multiple Messages } \\
\hline Not sure & 0.547 & $0.524(21)$ & $0.563(32)$ \\
\hline Y (cooperation) & 0.752 & $0.730(159)$ & $0.769(208)$ \\
\hline $\mathrm{Z}$ (defection) & 0.150 & $0.125(8)$ & $0.167(12)$ \\
\hline Total & 0.700 & $0.681(188)$ & $0.714(252)$ \\
\hline \multicolumn{4}{|l|}{ Pledge } \\
\hline Not sure & 0.369 & $0.368(527)$ & $0.389(18)$ \\
\hline Y (cooperation) & 0.887 & $0.876(250)$ & $1.000(24)$ \\
\hline $\mathrm{Z}$ (defection) & 0.049 & $0.025(40)$ & $1.000(1)$ \\
\hline Total & 0.519 & $0.507(817)$ & $0.744(43)$ \\
\hline
\end{tabular}

\section{Table 5: Communication as a signal of intentions}

Notes to Table 5: this table only considers (i) messages sent by the subject about her intended play and (ii) the concordance between the message and the subject's the action immediately following the message. Number of observations is in parenthesis. 
The probit regression in Table 4, column 3 interacts the treatment dummies with a variable measuring the number of cooperative messages sent by other subjects in the period. Results confirm that the greater is the number of cooperative messages observed, the higher is the cooperation rate for the representative subject. In addition, the regression shows that the lack of messages signaling the intention to cooperate was taken as a signal of the intention to defect. If others did not make public their intention to cooperate, then cooperation was lower in treatments with structured communication than the treatment without communication. This finding supports the interpretation that sending a public message of cooperation was perceived as signaling truthfully the intention of the sender.

All this evidence suggests that the lack of public messages of cooperation was interpreted as a lukewarm desire to coordinate on cooperation, whereas the presence of cooperative messages was interpreted as a strong desire for coordination on cooperation. This explains why high levels of cooperation are observed when many cooperative messages are made public, and low levels of cooperation emerge otherwise.

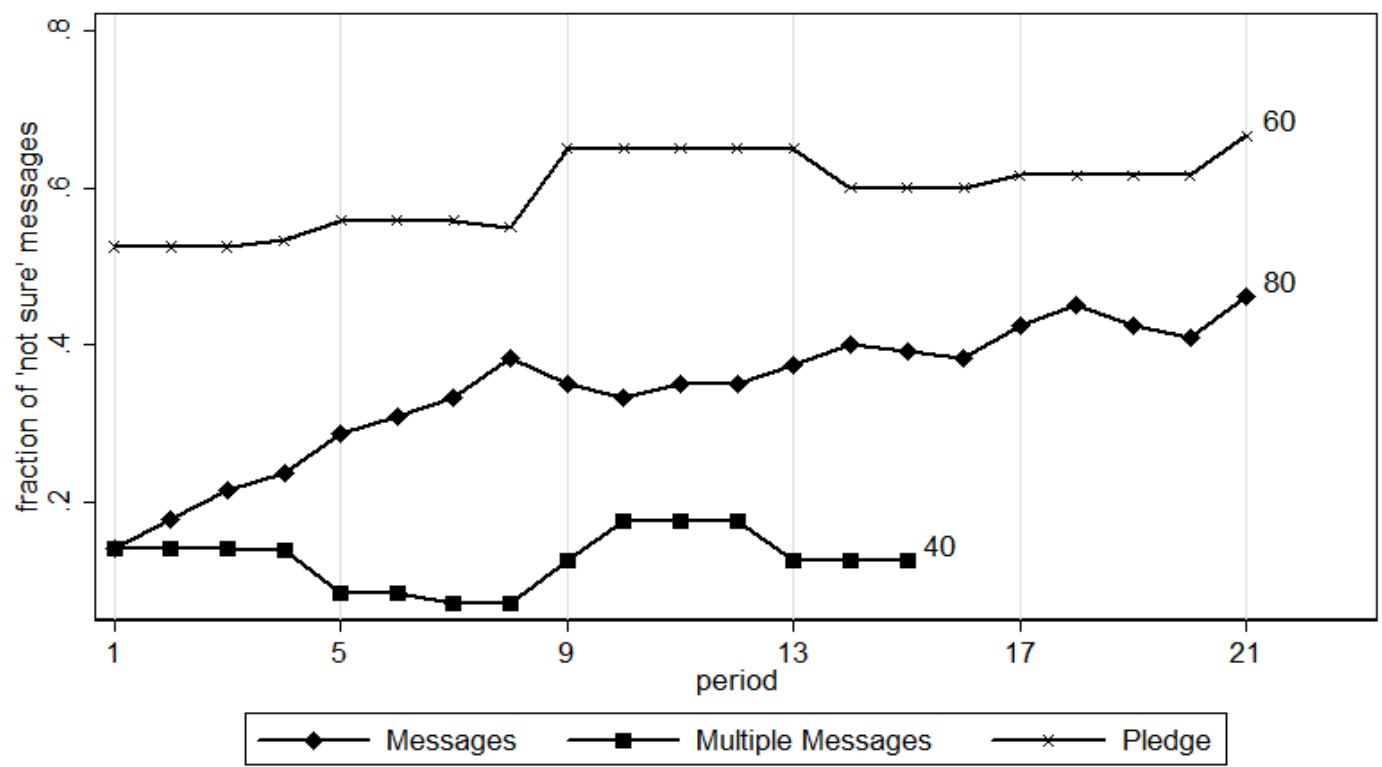

Figure 2: Neutral messages 
Notes to Figure 2: One observation is a message of the subject's intended play for the period. In period one, $N=200$ for each line. Cycle length reported was truncated after period 21 due to the low number of observations for periods after 21 in some treatments. The number of observations in period 21 is reported at the end of the line.

Result 4: Subjects used structured communication for two opposite goals: either to coordinate on cooperation or to capture short-run rents through deception.

Because in the experiment messages were informative, they shaped beliefs. From Result 3, one can conjecture that the more cooperative messages were made public, the stronger was the belief that a social norm of cooperation could be supported. This means that subjects could make several uses of communication. The socially desirable, or benevolent, use of communication is to help coordination on cooperation by reinforcing the belief that the sender of a cooperative message will cooperate. However, there is also a socially undesirable use of communication. Subjects could behave deceptively by sending a cooperative message to reinforce the belief in a cooperative outcome while intending to defect.

The data provide evidence on these conflicting uses of public messages. Based on the messages sent and observed, in the data there exist cases in which one can quantify a lower bound for the incidence of deceptive and benevolent use of communication in the experiment. For this purpose, we define two types of subjects. A deceptive subject is someone who, at least once during the cycle, signaled her intention to cooperate, observed that everyone else also shared a similar intention, and defected the period immediately following such communication. A benevolent subject either cooperated in all those periods of a cycle when all other subjects signaled the intention to cooperate; or cooperated in all periods of a cycle when she made public her intention to cooperate. Clearly, not all subjects fall into one of 
these two types because either subjects behaved differently or never faced a situation in which they could behave deceptively or benevolently. ${ }^{12}$

The prevalent use of communication in all treatments is benevolent. In the Messages treatment $41.9 \%$ of subjects were deceptive and $49.5 \%$ were benevolent when given the opportunity (no.obs. 52/124, 95/192, respectively); in the Multiple Message treatment 27.7\% were deceptive and $68.0 \%$ were benevolent $(31 / 112,134 / 197)$; in the Pledge treatment $0.0 \%$ were deceptive and $77.8 \%$ were benevolent $(0 / 4,88 / 113)$.

This finding suggests that what prevented structured communication from facilitating the implementation of a social norm of cooperation is not entirely explained by limitations in the message space. As we have seen messages are empirically informative and not necessarily theoretically credible. The crux of the matter is that there were subjects who made a deceptive use of communication. Deception diluted the meaningfulness of the observed public messages of cooperation, and reduced the value of making public the intention to cooperate.

Table 6 provides further support for Result 4. In a probit regression, we explain the cooperation actions $(0=$ defect, $1=$ cooperate $)$ using as independent variables the messages made public in the economy, controlling for period effects, cycle order and duration. Subjects were not always more likely to cooperate when they observed several cooperative messages. A subject who sent a cooperative message was more likely to cooperate when two or three others signaled their intention to cooperate, and the effect was highly significant in all three treatments. This supports the view that communication was used to foster coordination on a

\footnotetext{
${ }^{12}$ Our definition aims to pin down a lower bound for deceptive behavior. For example, someone who sends a cooperative message, then observes two others who sent a cooperative message and one who sent a defection message is not classified as being deceptive even if she defects in the following period. Similarly, we cannot say whether a subject is benevolent if she never sent a cooperative message and she never observed three cooperative messages from the others. Hence, we have fewer than 200 observations per treatment that we can use to classify subjects as deceptive or benevolent type.
} 
social norm of cooperation. On the other hand, subjects who did not send a cooperative message, and also observed at least two cooperative messages were less likely to cooperate in the Messages and Multiple Messages treatments. This is evidence that some subjects used communication in an opportunistic way.

\begin{tabular}{llll}
\hline $\begin{array}{l}\text { Dependent variable: cooperation } \\
\text { marginal effects from probit regressions }\end{array}$ & Messages & $\begin{array}{l}\text { Multiple } \\
\text { Messages }\end{array}$ & Pledge \\
\hline $\begin{array}{l}\text { msg_sent (=1 if the subject signaled the intention } \\
\text { to cooperate) }\end{array}$ & 0.071 & $-0.398^{* * *}$ & $0.558^{* * *}$ \\
& $(0.170)$ & $(0.091)$ & $(0.043)$ \\
msg_observed (=1 if the subject observed 2 or 3 & & & \\
cooperative messages) & $-0.093^{* * *}$ & $-0.365^{* * *}$ & $0.088^{*}$ \\
& $(0.031)$ & $(0.064)$ & $(0.047)$ \\
(msg_sent.) x (msg_observed) & $0.333^{* * *}$ & $0.704^{* * *}$ & $0.313^{* * *}$ \\
& $(0.067)$ & $(0.134)$ & $(0.035)$ \\
cycle 2 & $-0.308^{* * *}$ & -0.106 & $-0.135^{*}$ \\
& $(0.003)$ & $(0.166)$ & $(0.072)$ \\
cycle 3 & $0.047^{* *}$ & $-0.115^{*}$ & 0.001 \\
& $(0.021)$ & $(0.062)$ & $(0.007)$ \\
cycle 4 & 0.045 & $-0.125^{* *}$ & $-0.221^{* *}$ \\
& $(0.053)$ & $(0.050)$ & $(0.105)$ \\
cycle 5 & -0.044 & $-0.156^{* * *}$ & $0.028^{* * *}$ \\
& $(0.040)$ & $(0.017)$ & $(0.005)$ \\
lagduration & $-0.018^{*}$ & 0.004 & $-0.004^{* *}$ \\
communication (1 in periods $1,5,9, .)$. & $(0.010)$ & $(0.003)$ & $(0.002)$ \\
& & $0.078^{*}$ & $0.087^{* *}$ \\
\hline Pseudo R-squared & & $(0.042)$ & $(0.040)$ \\
Observations & 0.292 & 0.112 & 0.335 \\
\end{tabular}

Table 6: Effect of signaling cooperative intentions on cooperation

Notes to Table 6: We regress the binary choice of cooperation/defection on three main regressors, as well as standard control variables (duration of the previous cycle, cycle and period dummies, individual fixed effects, and a dummy for periods in which communication was possible). The first regressor is a dummy that takes value 1 when the subject signaled her intention to cooperate (i.e., sent a message $Y$ "for herself"). The second regressor is also a dummy, which takes value 1 in periods when communication was possible and the subject observed at least two cooperative messages from others. The third regressor is an interaction term between the first two. Standard errors robust for clustering at the session level are reported in parentheses. ${ }^{*}$ significant at $10 \%$; ** significant at $5 \%$; *** significant at $1 \%$. Individual fixed effects.

The regression also provides evidence that the possibility to audit the consistency between actions and messages removed the incentives to make a deceptive use of communication 
opportunities and effectively introduced the possibility of individual commitment as a way to build trust. In the Pledge treatment, subjects who signaled a cooperative intention were significantly more likely to cooperate even when no one else publicly signaled their intention to cooperate. Moreover, subjects who did not signal their intention to cooperate, also raised their cooperation level when they observed cooperative messages, albeit to a lesser extent due to the presence of opportunistic subjects.

Finally, the regression provides support for the view that neutral messages "not sure" had a negative connotation. In the Multiple Messages treatment, subjects who publicly signaled a cooperative intention and saw that less than two other subjects did the same, were less likely to cooperate than subjects who did not send a cooperative message. We know also that very few subjects sent explicit signals of defection (message $Z$ ).

Result 5: In the Pledge treatment, there was no deceptive use of communication thanks to the extensive use of auditing. Defectors paid to audit more often than cooperators.

The Pledge treatment substantially altered communication patterns. It increased the information content of communication (Result 3). The opportunity to audit transformed structured communication from cheap-talk into a form of public and unilateral commitment device, i.e., a credible pledge. A subject who sent a message signaling a cooperative intention, and then defected, suffered a loss if someone in the economy audited. As a consequence, the use of auditing removed the incentives to use communication deceptively, but it also exposed subjects who publicly "pledged" cooperation to the risk of being exploited by those uninterested in coordinating on the efficient outcome. Sending a public message of cooperation could be particularly risky because the pledge lasted for four periods. As a result, deception disappeared because of lack of cooperative pledges: a large fraction of explicit 
messages were simply replaced by neutral messages (Figure 2). The net effect was that coordination on cooperation declined relative to the no-communication treatment (Table 4).

On average, someone audited in $44.6 \%$ of periods, which is evidence that subjects desired to have a commitment technology. Paying one point to audit can be seen as an investment aimed at ensuring that those who signaled a cooperative intention were indeed committed to cooperation. As a result the truthfulness of messages increased in the Pledge treatment. A subject who signal a cooperative intention cooperated more frequently than in other treatments (Table 5). However, commitment could be used in one of two ways. To facilitate coordination on cooperation by assuring that others would also cooperate, i.e., by building trust that others are committed to cooperation. Or to facilitate rent extraction, which instead reduces trust in the cooperative efforts of others. ${ }^{13}$ Table 7 provides evidence for both uses of auditing. Cooperators who sent a cooperative message were responsible for $33.9 \%$ of auditing requests while defectors who sent a neutral message were responsible for $46.2 \%$ of auditing requests. This evidence supports the view that introducing a mechanism to transform public statements into binding promises did not make it easier to implement a social norm of cooperation. Through auditing cooperators were simply kept hostage by defectors.

\begin{tabular}{llllll}
\hline \multirow{2}{*}{ Action chosen } & \multicolumn{2}{c}{ Subject's message about her intended play } & Total & $N$ \\
& Not sure & Y (cooperation) & $\mathrm{Z}$ (defection) & & \\
& $\%$ & $\%$ & $\%$ & $\%$ & \\
\hline Y (cooperation) & 11.1 & 33.9 & 0.2 & $\mathbf{4 5 . 3}$ & 191 \\
Z (defection) & 46.2 & 4.0 & 4.5 & $\mathbf{5 4 . 7}$ & 231
\end{tabular}

\footnotetext{
${ }^{13}$ To fix ideas, consider an economy where one subject sent a neutral message and then defected after observing three cooperative messages. Those who sent a cooperative message could not profit from defecting if auditing takes place, because they would lose 5 points in expectation. Notice that the defector has an incentive to audit: she will earn 30 minus 1 point instead of a maximum of 25. Cooperators who sent a cooperative message have an incentive to audit when everyone else sends a cooperative message, because doing so removes the incentives to be deceptive.
} 


\begin{tabular}{llllll}
\hline \hline Total & 57.3 & 37.9 & 4.7 & $\mathbf{1 0 0 . 0}$ & 422 \\
$N$ & 242 & 160 & 20 & 422 & \\
\hline
\end{tabular}

\section{Table 7: Auditing in the Pledge treatment}

Notes to Table 7: one observation per subject per period. The table reports the distribution of auditing choices in the population according to the signal made public by the subject (message sent "for onself") and the action subsequently chosen. The 422 instances of requests for auditing amounts to $100 \%$ of the observations in the table.

Result 6: Signaling intentions through structured communication did not have positive impact on profits in the economy.

Evidence for Result 6 is given by the regressions in Table 8. We regress the average profit in each economy on the average number of public statements that were explicit about the sender's intended play ("Y" or "Z" messages "for oneself"), controlling for cycle order and length.

\begin{tabular}{lccc}
\hline Dependent variable: & Messages & Multiple Messages & Pledge \\
Average profit per economy & $(1)$ & $(2)$ & $(3)$ \\
\hline Number of explicit messages & 3.514 & 0.689 & $-0.189^{* *}$ \\
regarding the subject's intended & $(1.560)$ & $(0.885)$ & $(0.009)$ \\
play & & & \\
Number of explicit messages & -2.165 & & \\
regarding play suggested to & $(2.205)$ & $(.111$ & $1.876^{* * *}$ \\
others (match and everyone else) & & & $(0.002)$ \\
& & & \\
Cycle 2 & -2.927 & -0.295 & -2.847 \\
& $(0.689)$ & $(1.632)$ & $(0.849)$ \\
Cycle 3 & 1.537 & -0.831 & $-2.760^{* *}$ \\
& $(3.408)$ & $(0.176)$ & $(0.108)$ \\
Cycle 4 & 0.675 & -0.615 & $-1.053^{*}$ \\
& $(1.839)$ & $(0.946)$ & $(0.090)$ \\
Cycle 5 & -0.536 & $-1.326^{*}$ & $-2.275^{* *}$ \\
& $(1.450)$ & $(0.105)$ & $(0.092)$ \\
Cycle length in periods & $-0.145^{* *}$ & $-0.262^{*}$ & $-0.125^{* * *}$ \\
& $(0.007)$ & $(0.037)$ & $(0.000)$ \\
Constant & $17.577^{*}$ & 16.494 & $17.752^{* *}$ \\
& $(2.185)$ & $(5.257)$ & $(0.281)$ \\
\hline Observations & 50 & 50 & 50 \\
$\mathrm{R}^{2}$ & 0.317 & 0.142 & 0.342 \\
\hline
\end{tabular}


Table 8: Structured communication and profits

Notes to Table 8: OLS regression where the dependent variable is profits. For the Pledge treatment the dependent variable is gross profits, i.e., fees and costs associated to auditing are not removed from the total. Standard errors robust for clustering at the session level are reported in parentheses. * significant at 10\%; ** significant at 5\%; *** significant at $1 \%$.

In the Pledge treatment there was a significantly negative association between the number of messages signaling intentions and the profit in the economy. Moreover, there was a positive association between the message sent to suggest play to others and the profit in the economy. None of these effects is significant in the Messages and Multiple Messages treatments. These findings suggest that making binding promises of play did not help to increase profits because of the exploitative use of auditing made by defectors; instead, subjects relied on a more indirect way to signal their cooperative intention by using nonbinding promises, i.e., by suggesting the cooperative action to others. Contrary to the conjecture in Wilson and Sell (1997), augmenting a public communication technology in such a way that a message effectively amounts to a strong pledge, is not helpful in improving aggregate welfare in repeated social dilemmas.

\section{Discussion and conclusions}

The experimental literature has demonstrated that pre-play communication promotes social efficiency in a variety of settings, even when the socially efficient outcome is not a Nash equilibrium. One would expect cheap-talk to have a similar or even more beneficial impact in settings where the socially efficient outcome is a theoretical equilibrium, albeit one that is empirically infrequently observed (Camera and Casari, 2009). 
We have studied if communication could help to implement social norms of cooperation in a stable population of subjects who interacted with changing opponents. Through an experiment we studied five distinct communication technologies: no communication, chat, and different types of structured communication. With each technology, a subject initially sent a message to everyone in the economy, observed everyone's messages, and then randomly met an opponent to play a prisoner's dilemma. Subjects could observe past cooperation rates in the economy but not individual histories, so reputation could not be built. This design resembles the anonymous and impersonal interaction that takes place in large societies. Because the interaction was indefinitely repeated, all treatments admitted multiple equilibria, including the efficient outcome. Subjects could sustain the efficient outcome through a social norm of cooperation based on community enforcement of defections. We report that only free-form communication was effective in raising cooperation. With structured communication, subjects tended to act in accordance with their own message, and to react to the messages seen. Yet, structured communication did not significantly increase cooperation relative to no communication. This is especially surprising because in the experiment subjects interacted anonymously and could not develop a reputation.

This experiment allows us to disentangle some of the elements that do or do not make communication effective in raising social welfare. In particular, the design allows us to assess the impact of different roles of public statements: for coordination, for commitment, and for deception. We report that deceptive and benevolent uses of communication coexisted. Most subjects valued the coordination and commitment roles of communication. However, different subjects used communication for different purposes. In particular, with structured communication a minority of subjects behaved deceptively, which undermined trust and rendered communication ineffective in raising social welfare. 
As in most papers with structured communication, the experiment includes a treatment in which subjects simultaneously send a message before choosing their action (Messages treatment). However, we also study the case when subjects can revise multiple times their public message after observing the messages of everyone else and before deciding on their action (Multiple Messages treatment). Given the underlying uncertainty about others' strategies, having the opportunity to revise messages to achieve consensus should foster the emergence of a social norm of cooperation. If communication is primarily used to facilitate coordination on the efficient outcome, then we would expect higher cooperation rates in Multiple Messages than in Messages. On the contrary, we report that cooperation rates in the two treatments did not differ.

Talk being cheap, it is perhaps the credibility of messages that makes communication ineffective in raising cooperation rates. In the Pledge treatment subjects could solve credibility problems. Through auditing, anyone could verify the concordance of messages sent with actions subsequently taken. If auditing occurred, then those who broke their pledge were sanctioned. Auditing introduced the possibility of voluntary individual commitment. If making binding promises public is valuable to build trust, then one would expect a higher cooperation rate in the Pledge than in the Messages treatment. On the contrary, we report that cooperation significantly fell.

With our design we can also detect whether the use of communication is benevolent or deceptive, and quantify the relative incidence. Deception, i.e., falsely signaling intentions, can be the reason why structured communication is ineffective. We report that the prevalent use of communication was benevolent, but there was also a substantial use of deception, especially in the Messages treatment where around $42 \%$ of subjects sent at least one deceptive message. The possibility to make a pledge eliminated deception, but it did so at the expense of crowding-out explicit communication. In the Pledge treatment explicit messages 
were much more informative because a subject's pledge to cooperate was fulfilled $89 \%$ of the times. However this also reduced the volume of explicit messages because subjects who pledged cooperation were easy targets for opportunistic defectors. Hence, subjects switched to sending neutral messages. Moreover, sending a binding public message amounted to being the first mover in a game, which lowered the usefulness of communication, as the sender of the message could not react to the messages later observed. In sum, contrary to the conjecture in Wilson and Sell (1997), the experimental results suggest that binding promises are not the key to increase the effectiveness of communication in sustaining cooperation. The above findings suggest that what prevents structured communication from facilitating full efficiency is not so much the limitation in the message space or difficulties in interpreting messages. To be effective, the communication technology should support a high volume of messages, while reducing the incentive for deception. None of our structured communication technologies exhibited both of these properties.

Our findings for structured communication mirror some of the results obtained in finitely repeated social dilemmas, where cheap-talk can have no impact or even a negative impact on social welfare (Wilson and Sell, 1997, Duffy and Feltovich, 2006). This suggests that the same behavioral mechanism tied to communication in finitely repeated games-where only defection is an equilibrium-is also present when the game is indefinitely repeated, where cooperation is also an equilibrium. In a way, it is surprising that the behavioral impact of structured communication is unaffected by the change in equilibrium set, especially because of the associated introduction of a non-trivial coordination problem. Only in the chat treatment communication played a positive role. Perhaps the possibility to convey strategies and verbally punish defectors helped the implementation of a social norm of cooperation. 


\section{References}

Abreu, D., D. Pearce, and E. Stacchetti (1993), "Renegotiation and Symmetry in Repeated Games." Journal of Economic Theory, 60(2), 217-240.

Andersson, O. and E. Wengstrom (2010) More Communication, Less Cooperation: Experimental Evidence from Multi-stage Games, working paper.

Aumann, R. (1990), "Nash Equilibria are not Self-enforcing." in Economic Decision Making: Games, Econometrics and Optimization (J.J. Gabszewicz; J.F. Richard and L.A. Wolsey Eds.) Elsevier, Amsterdam, New York.

Baumann, Z. (2000), Liquid Modernity, Polity Press.

Bigoni, M., S. O. Fridolfsson, C. Le Coq, and G. Spagnolo (2009). "Fines, Leniency and Rewards in Antitrust: An Experiment." CEPR Discussion Paper No. DP7417.

Blume, A. and A. Ortmann (2007), "The Effects of Costless Pre-play Communication: Experimental Evidence from Games with Pareto-ranked Equilibria." Journal of Economic Theory, 132(1), 274-290.

Bochet, O., T. Page and L. Putterman (2006), "Communication and punishment in voluntary contribution experiments.” Journal of Economic Behavior \& Organization, 60(1), 11-26.

Bornstein, G., A. Rapoport, L. Kerpel, and T. Katz (1989). "Within- and Between-Group Communication in Intergroup Competition for Public Goods." Journal of Experimental Social Psychology, 25, 422-36.

Camera, G., and M. Casari (2009). "Cooperation among strangers under the shadow of the future." American Economic Review, 99(3), 979-1005.

Cason, T. N. and V.-L. Mui (2010), "Coordinating Resistance through Communication and Repeated Interaction.” Unpublished manuscript, Monash University.

Cooper, R., D. V. DeJong, R. Forsythe, and T.W. Ross (1992). "Communication in Coordination Games." Quarterly Journal of Economics, 107, 739-771

Cooper, D. J. and K.-U. Kuhn (2010), "Communication, Renegotiation, and the Scope for Collusion." Unpublished manuscript, Florida State University.

Crawford, V. (1998), "A Survey of Experiments on Communication via Cheap Talk." Journal of Economic Theory, 78(2), 286-298.

Dal Bó, P. (2005), "Cooperation under the Shadow of the Future: Experimental Evidence from Infinitely Repeated Games.” American Economic Review, 95(5), 1591-1604.

Duffy, J. and N. Feltovich (2006). "Words, Deeds and Lies: Strategic Behavior in Games with Multiple Signals.” Review of Economic Studies, 73, 669-688.

Duffy, J., and J. Ochs (2009). "Cooperative Behavior and the Frequency of Social Interaction." Games and Economic Behavior, 66, 785-812.

Ellison, G. (1994), "Cooperation in the Prisoner's Dilemma with Anonymous Random Matching." Review of Economic Studies, 61, 567-88.

Farrell, J. and M. Rabin (1996). "Cheap talk." Journal of Economic Perspectives 10, 103118. 
Kandori, M. (1992) "Social Norms and Community Enforcement." Review of Economic Studies, 59, 63-80.

Ostrom, E. (2010). Beyond Markets and States: Polycentric Governance of Complex Economic Systems. American Economic Review, 100, 641-672

Ostrom, E., J. Walker, and R. Gardner (1992), "Covenants With and Without a Sword: SelfGovernance is Possible." American Political Science Review, 86, 404-417

Roth, A. E., and K. Murnighan (1978), "Equilibrium Behavior and Repeated Play of The Prisoner's Dilemma." Journal of Mathematical Psychology, 17: 189-98.

Sally, D. (1995), "Conversation and Cooperation in Social Dilemmas: a Meta-analysis of Experiments from 1958 to 1992." Rationality and Society, 7(1), 58-92.

Strassmair C. and M. Sutter (2009), "Communication, cooperation and collusion in team tournaments - An experimental study." Games and Economic Behavior 66, 506-525.

Van Damme, E. (1989), "Renegotiation-proof Equilibria in Repeated Prisoners' Dilemma." Journal of Economic Theory, 47(1), 206-217.

Wilson, R. K., and J. Sell (1997). "Liar, Liar... Cheap Talk and Reputation in Repeated Public Goods Settings." Journal of Conflict Resolution, 41 (5), 695-717 


\title{
Communication, commitment, and deception in social dilemmas: experimental evidence
}

\author{
Gabriele Camera, Marco Casari, and Maria Bigoni
}

\section{Appendix A}

\begin{tabular}{lccc}
\hline \hline treatments & n1 & n2 & p-value \\
\hline No-communication vs. Messages & 50 & 50 & 0.4984 \\
No-communication vs. Multiple Messages & 50 & 50 & 0.1096 \\
No-communication vs. Pledge & 50 & 50 & 0.9780 \\
No-communication vs. Chat & 50 & 25 & 0.0000 \\
Messages vs. Multiple Messages & 50 & 50 & 0.4095 \\
Messages.vs. Pledge & 50 & 50 & 0.3246 \\
Messages.vs. Chat & 50 & 25 & 0.0000 \\
Multiple Messages vs. Pledge & 50 & 50 & 0.0604 \\
Multiple Messages vs. Chat & 50 & 25 & 0.0000 \\
Pledge. vs. Chat & 50 & 25 & 0.0000 \\
\hline
\end{tabular}

Table A1: rank-sum tests across treatments - cooperation (individual decision)

\begin{tabular}{lccl}
\hline \hline treatments & n1 & n2 & p-value \\
\hline No-communication vs. Messages & 50 & 50 & 0.5222 \\
No-communication vs. Multiple Messages & 50 & 50 & 0.8221 \\
No-communication vs. Pledge & 50 & 50 & 0.0763 \\
No-communication vs. Chat & 50 & 25 & 0.0000 \\
Messages vs. Multiple Messages & 50 & 50 & 0.7563 \\
Messages vs. Pledge & 50 & 50 & 0.0238 \\
Messages vs. Chat & 50 & 25 & 0.0000 \\
Multiple Messages vs. Pledge & 50 & 50 & 0.0901 \\
Multiple Messages vs. Chat & 50 & 25 & 0.0000 \\
Pledge. vs. Chat & 50 & 25 & 0.0000 \\
\hline
\end{tabular}

Table A2: rank-sum tests across treatments - coordination on cooperation 


\begin{tabular}{lrrrrrr}
\hline \hline subject's messages & Number of cooperative messages by others & & \\
self|match|else & 0 & 1 & 2 & 3 & Total & $\mathrm{N}$ \\
\hline N.S N.S. N.S. & $45.3 \%$ & $44.9 \%$ & $35.5 \%$ & $62.8 \%$ & $45.9 \%$ & 988 \\
N.S. Coop. Coop. & $0.0 \%$ & $0.0 \%$ & $0.0 \%$ & $0.0 \%$ & $0.0 \%$ & 12 \\
Coop. N.S. N.S. & $75.0 \%$ & $72.7 \%$ & $93.3 \%$ & $92.9 \%$ & $90.7 \%$ & 118 \\
Coop. Coop. N.S. & $0.0 \%$ & $9.5 \%$ & $42.7 \%$ & $42.9 \%$ & $31.3 \%$ & 182 \\
Coop. Coop. Coop. & $44.8 \%$ & $43.5 \%$ & $71.8 \%$ & $80.6 \%$ & $67.0 \%$ & 1510 \\
Defect Coop. N.S. & $0.0 \%$ & $0.0 \%$ & $0.0 \%$ & $0.0 \%$ & $0.0 \%$ & 5 \\
Defect Defect Coop. & & $0.0 \%$ & $0.0 \%$ & $0.0 \%$ & $0.0 \%$ & 6 \\
all other messages & $5.9 \%$ & $9.4 \%$ & $11.4 \%$ & $17.9 \%$ & $11.6 \%$ & 199 \\
Total & $39.9 \%$ & $39.2 \%$ & $56.7 \%$ & $71.2 \%$ & $54.7 \%$ & 3020 \\
\hline N & 286 & 760 & 1147 & 827 & 3020 & \\
\hline
\end{tabular}

Table A3: truthfulness of subjects' messages - treatment Messages

N.S.= not sure $Y=$ cooperate $Z=$ defect

\begin{tabular}{lrrrrrr}
\hline \hline subject's messages & Number of cooperative messages by others & & \\
self|match|else & 0 & 1 & 2 & 3 & Total & N \\
\hline N.S. N.S. N.S. & & $66.7 \%$ & $50.0 \%$ & $54.8 \%$ & $53.8 \%$ & 52 \\
Coop. N.S. N.S. & & & & $100.0 \%$ & $100.0 \%$ & 3 \\
Coop. Coop. N.S. & & $50.0 \%$ & $0.0 \%$ & $25.0 \%$ & $33.3 \%$ & 9 \\
Coop. Coop. Coop. & $100.0 \%$ & $54.5 \%$ & $77.7 \%$ & $77.8 \%$ & $76.4 \%$ & 351 \\
Defect Coop. N.S. & & & $0.0 \%$ & $0.0 \%$ & $0.0 \%$ & 4 \\
Defect Defect Coop. & & & $100.0 \%$ & & $100.0 \%$ & 1 \\
all other messages & & & $0.0 \%$ & $33.3 \%$ & $25.0 \%$ & 20 \\
Total & $100.0 \%$ & $55.2 \%$ & $70.3 \%$ & $71.4 \%$ & $70.0 \%$ & 440 \\
\hline N & 1 & 29 & 158 & 252 & 440 & \\
\hline
\end{tabular}

Table A4: truthfulness of subjects' messages - treatment Multiple Messages

\begin{tabular}{lrrrrrr}
\hline \hline subject's messages & \multicolumn{7}{c}{ Number of cooperative messages by others } & & \\
self|match|else & 0 & 1 & 2 & 3 Total & N \\
\hline N.S. N.S. N.S. & $22.6 \%$ & $27.8 \%$ & $41.4 \%$ & $50.0 \%$ & $29.1 \%$ & 296 \\
N.S. Coop. Coop. & $36.6 \%$ & $54.1 \%$ & $45.9 \%$ & $33.3 \%$ & $45.4 \%$ & 205 \\
Coop. N.S. N.S. & & $100.0 \%$ & & & $100.0 \%$ & 1 \\
Coop. Coop. N.S. & $25.0 \%$ & $50.0 \%$ & $100.0 \%$ & $100.0 \%$ & $73.7 \%$ & 19 \\
Coop. Coop. Coop. & $85.5 \%$ & $90.3 \%$ & $96.1 \%$ & $100.0 \%$ & $90.7 \%$ & 248 \\
Defect Coop. N.S. & $0.0 \%$ & $0.0 \%$ & $0.0 \%$ & & $0.0 \%$ & 10 \\
all other messages & $9.7 \%$ & $50.0 \%$ & $36.4 \%$ & $100.0 \%$ & $33.3 \%$ & 81 \\
Total & $40.9 \%$ & $54.6 \%$ & $59.3 \%$ & $74.4 \%$ & $51.9 \%$ & 860 \\
\hline N & 291 & 359 & 167 & 43 & 860 & \\
\hline
\end{tabular}

Table A5: truthfulness of subjects' messages - treatment Pledge

\begin{tabular}{lllllll}
\hline \hline treatments & 1 & 2 & 3 & 4 & 5 & Total \\
\hline
\end{tabular}




\begin{tabular}{lcccccc}
\hline No-communication & 24 & 19 & 47 & 25 & 14 & 129 \\
Messages & 13 & 11 & 7 & 41 & 53 & 125 \\
Multiple Messages & 20 & 23 & 20 & 24 & 22 & 109 \\
& 2 & 1 & 32 & 5 & 2 & 42 \\
Pledge & 1 & 15 & 9 & 4 & 6 & 35 \\
& 4 & 9 & 3 & 15 & 8 & 39 \\
Chat & 47 & 2 & 10 & 3 & 13 & 75 \\
& 3 & 7 & 2 & 42 & 25 & 79 \\
& 14 & 70 & 40 & 25 & 10 & 159 \\
\hline
\end{tabular}

Table A6: cycle duration 


\section{Appendix B: Instructions for treatment Messages (not for publication)}

\section{Overview}

This is an experiment in decision-making. Purdue University has provided funds for this research. The instructions are simple. If you follow them carefully and make good decisions, you can earn an appreciable amount of money. These earnings will be paid to you in cash at the end of the experiment.

We ask that you not talk with one another for the duration of the experiment. Please turn off your cell-phones. Do not use e-mail.

During the course of this experiment, you will be called upon to make decisions in several periods. The experiment is divided into five sequences of periods and each sequence is referred to as a cycle.

- At the beginning of a cycle, each participant in this room will be randomly assigned to a set.

- In each set there will be four persons.

- $\quad$ For the whole duration of a cycle, you will interact exclusively with the three other participants in that set and nobody else.

- You will never meet again these participants in the following cycles.

In each period of a cycle:

- In each period you will be matched to one other participant selected at random from the set you are assigned to. We will refer to this person as "your match."

- You will not be informed of the identity of your match. Hence, you do not know when you have already interacted with that person in previous periods of the same cycle.

- $\quad$ You and your match will interact according to the rules described in the upper portion of your screen. The rules will be explained in a moment.

After each period you will be re-matched to a participant chosen at random from the set you are assigned to. There is one chance out of three that you will be matched with any given person in your set. 


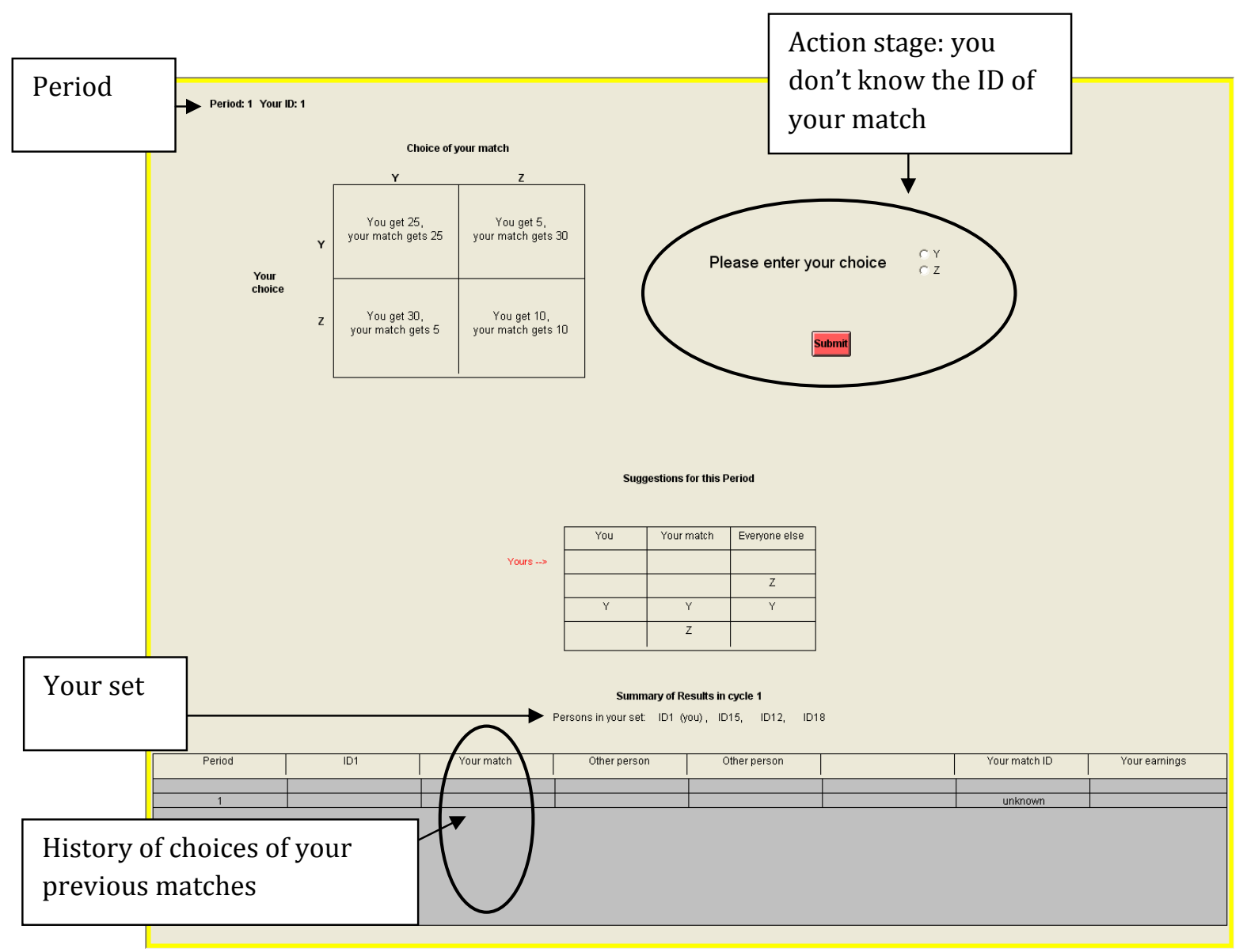

$\underline{\text { Interaction rules }}$

Each period is divided into two stages. In the suggestion stage everyone will have an opportunity to exchange information with others in their set. In the suggestion stage, you do not earn any points. In the action stage you interact only with your match and you can earn points. We now explain the action stage and later will explain suggestion stage.

Action stage. You and your match can make either of two choices, Y or Z. The points you earn in the action stage depend upon both the choice you make and the choice made by your match in that stage. As the payoff table on your screen (above) indicates, there are four possible outcomes for the action stage:

1. If both of you choose $Y$ then: you both earn 25 points.

2. If you choose $\mathrm{Y}$ and your match chooses $\mathrm{Z}$ then: you earn $\mathbf{5}$ points and your match earns $\mathbf{3 0}$ points.

3. If you choose $\mathrm{Z}$ and your match chooses $\mathrm{Y}$ then: you earn 30 points and your match earns 5 points. 
4. If you both choose $\mathrm{Z}$ then: you both earn 10 points.

To make your choice, click the button next to either Y or Z. You may change your mind at any time prior to clicking the "Submit" button by simply clicking on the button next to Y or Z. You are free to choose $\mathrm{Y}$ or $\mathrm{Z}$ in every period. When you are satisfied with your choice, click the "Submit" button.

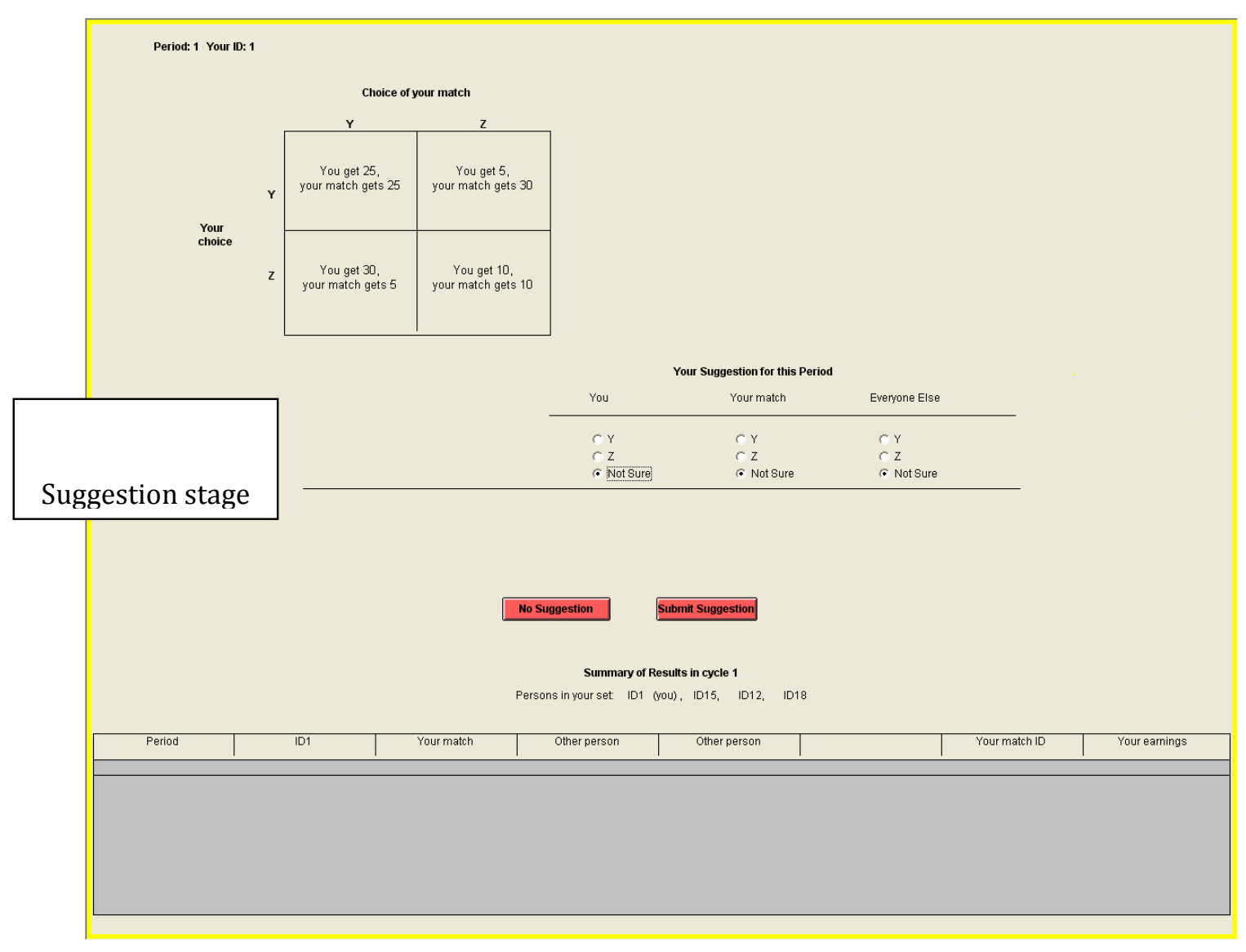

Suggestion stage. At the beginning of every period, you will have an opportunity to exchange suggestions about choices with everyone in your set. You are free to skip the suggestion stage entirely by clicking the "No Suggestion" button. The suggestion stage gives you the opportunity to suggest choice $\mathrm{Y}$ or $\mathrm{Z}$ for any person in your set. Your suggestion is shared with all people in your set.

You can make a suggestion for the current period. Suggestions concern choices for you, for your match, and for everyone else in your set. To share your suggestion with others, click the "Submit suggestion" button.

After the suggestion stage, all suggestions from people in your set will be displayed in a table in the middle of the screen. In the action stage, you are always free to choose $\mathrm{Y}$ or $\mathrm{Z}$ regardless of suggestions made by you or others. After all persons have made suggestions and choices, the results of the period will appear on your screen. 


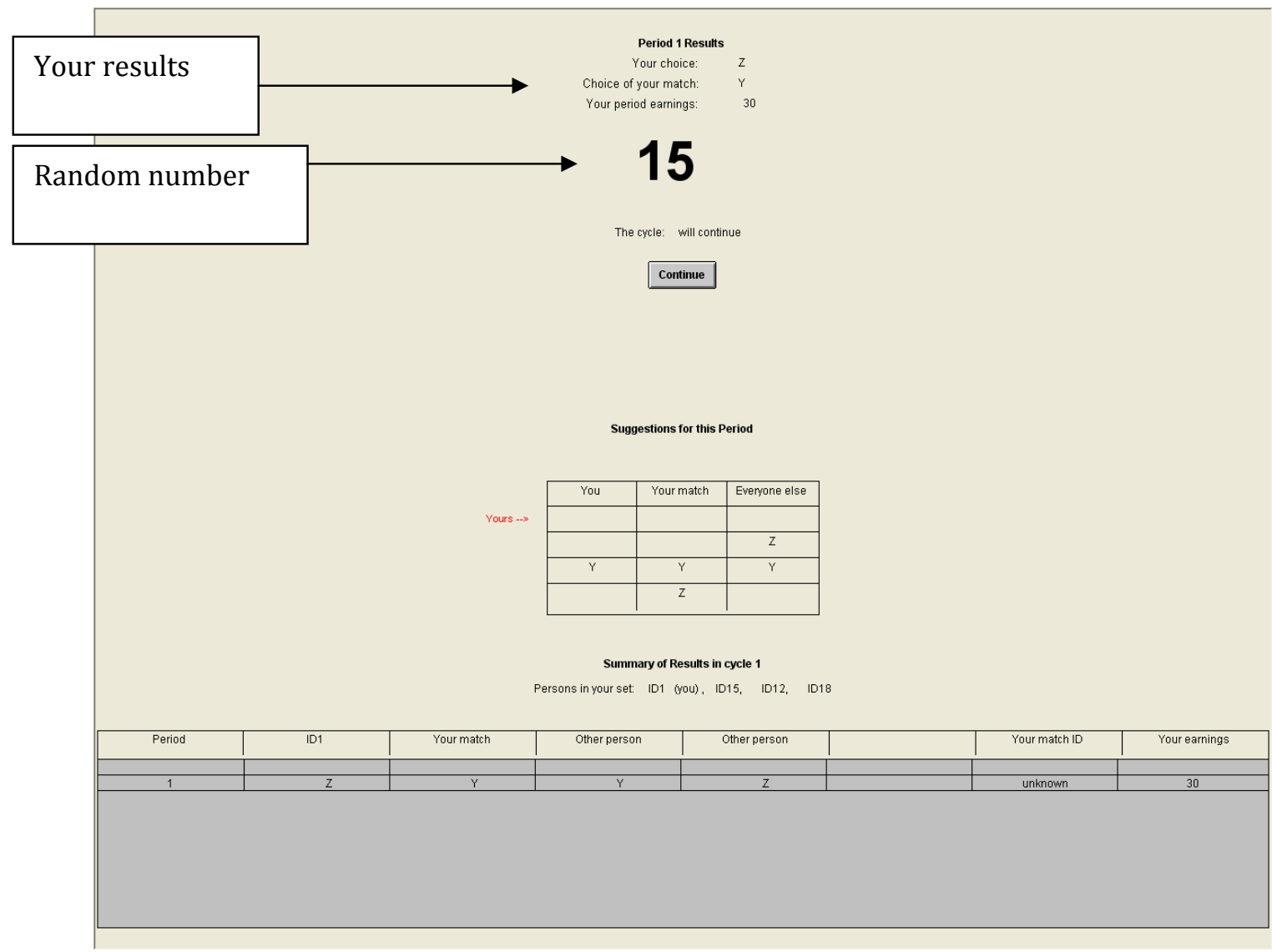

The result screen (above) will display the number of points you have earned for the period as well as the choices of all four persons in your set. The first column of the 'Summary of Results' table contains your past choices. The second column concerns the choices of your previous matches. The third and fourth columns list the choices of the other two persons in your set. Notice that choices in the column labeled "Your match" were most likely made by different persons in different periods. The same can be said for the two columns labeled "Other person". Please record your results for the period on your RECORD SHEET under the appropriate headings.

At this stage a ball will be drawn from an urn containing one hundred balls numbered from 1 to 100 . Each ball is equally likely to be selected. The computer program will randomly draw a ball and show the number on the result screen (above). If this random number is less than or equal to 95, then the cycle will continue into the next period. If this number is greater than 95 , then the cycle ends. Therefore, after each period there is a $95 \%$ chance that there will be another period of interactions in the cycle and a $5 \%$ chance that the cycle will end.

Suppose that a number less than or equal to 95 has been drawn. Then you press the "Continue" button to proceed. You will face the same decisional situation as in the previous period, but with a person selected at random from the set of participants you were assigned to. Remember that there are four participants in each set. 
Before making your choice, you may review all the outcomes in previous periods of the cycle by scrolling down the "Summary of Results" table. The table shows your past choices and the past choices of all persons in your set. You then choose either Y or Z. All choices for this period are recorded and added to the Summary of Results table in the lower portion of your screen. You then record the outcome and your point earnings for the period.

If the number drawn is greater than 95 then the cycle ends. When a cycle ends, you will be notified in a new screen. There will be a total of five cycles. The rules in the following cycles are the same as in the first, but you will interact with different persons. More precisely, after each cycle, new sets of persons will be formed. This assignment does not depend on actual choices. A participant will never interact with a person for more than one cycle.

Earnings

The points you earned in each period are added up. For every 10 points that you earn you will receive 13 cents (\$.13). Therefore, the more points you earn the more money you earn. You will be paid your earnings in cash and in private at the end of today's session. 


\section{$\underline{\text { Final Comments }}$}

First, do not discuss your choices or your results with anyone at any time during the experiment.

Second, your ID\# is private. Do not reveal it to anyone.

Third, since there is a $95 \%$ chance that at the end of a period the cycle will continue, you can expect, on average, to interact for 20 periods in a given cycle. However, since the stopping decision is made randomly, some cycles may be much longer than 20 periods and some others may be much shorter.

Fourth, remember that after each period you will be matched randomly to someone in the set you were assigned to. As there are four people in the set, the probability of you being matched with the same person in two consecutive periods of a cycle is $1 / 3$. You are not told the identity of your match.

Fifth, in the suggestion stage of every period you have an opportunity to suggest choices to people in your set. In the action stage everyone is free to choose $\mathrm{Y}$ or $\mathrm{Z}$ independently from any suggestion.

Sixth, the rules are the same in all five cycles. After a cycle, you will never meet again the same participants.

\section{Questions?}

Now is the time for questions. Does anyone have any questions before we begin? 


\section{Appendix C: Quiz}

QUIZ

1. The total number of cycles is

2. You are at the beginning of the cycle. How many periods do you expect the cycle will last, on average?

3. You are in period 15 of the cycle. How many additional periods do you expect, on average?

4. The number of participants in the experiment (total in the room) is

5. In a given cycle with how many participants could you interact with (i.e. number of people in a set)?

6. In a given period with how many participants do you interact with?

7. Other than your match, will you know at the end of the period the actions taken by people in your set?

8. Will you know at the end of the period the actions taken by participants outside your set?

9. Before choosing an action, will you know the ID of your match?

10. If ID 5 is in your set this cycle, is there any chance that ID 5 will be your match in future cycles?

11. How many points do you earn if both you and your match choose $\mathbf{Y}$ ?

12. If the experiment lasts 100 periods and everybody always chooses $\mathbf{Y}$, how many dollars are you going to earn?

13. How many points do you earn if you and your match choose $\mathbf{Z}$ ?

14. If the experiment lasts 100 periods and everybody always chooses $\mathbf{Z}$, how many dollars are you 


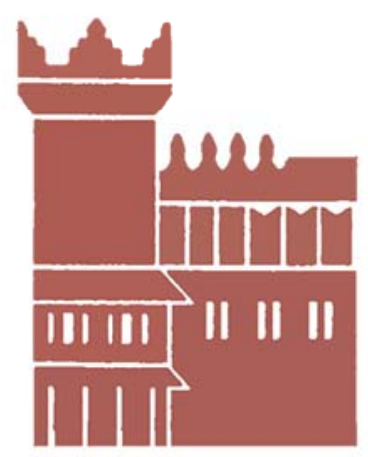

Alma Mater Studiorum - Università di Bologna DEPARTMENT OF ECONOMICS

Strada Maggiore 45

40125 Bologna - Italy

Tel. +39051 2092604

Fax +390512092664

http://www.dse.unibo.it 